\title{
Science Day Abstracts
}

K.M. Kline

March 12, 2001

U.S. Department of Energy

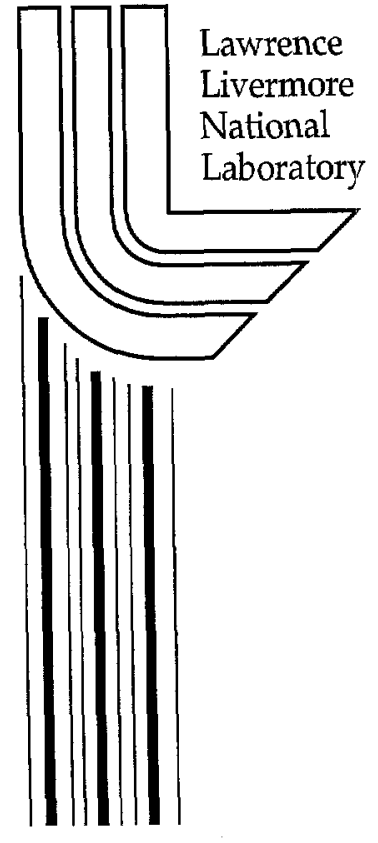




\section{DISCLAIMER}

This document was prepared as an account of work sponsored by an agency of the United States Government. Neither the United States Government nor the University of California nor any of their employees, makes any warranty, express or implied, or assumes any legal liability or responsibility for the accuracy, completeness, or usefulness of any information, apparatus, product, or process disclosed, or represents that its use would not infringe privately owned rights. Reference herein to any specific commercial product, process, or service by trade name, trademark, manufacturer, or otherwise, does not necessarily constitute or imply its endorsement, recommendation, or favoring by the United States Government or the University of California. The views and opinions of authors expressed herein do not necessarily state or reflect those of the United States Government or the University of California, and shall not be used for advertising or product endorsement purposes.

This work was performed under the auspices of the U.S. Department of Energy by the University of California, Lawrence Livermore National Laboratory under Contract No. W-7405-Eng-48.

This report has been reproduced directly from the best available copy.

Available electronically at http://www.doc.gov/bridge

Available for a processing fee to U.S. Department of Energy

And its contractors in paper from

U.S. Department of Energy

Office of Scientific and Technical Information

P.O. Box 62

Oak Ridge, TN 37831-0062

Telephone: (865) 576-8401

Facsimile: (865) 576-5728

E-mail: reports@adonis.osti.gov

Available for the sale to the public from

U.S. Department of Commerce

National Technical Information Service

5285 Port Royal Road

Springfield, VA 22161

Telephone: (800) 553-6847

Facsimile: (703) 605-6900

E-mail: orders@ntis.fedworld.gov

Online ordering: http://www.ntis.gov/ordering.htm

OR

Lawrence Livermore National Laboratory

Technical Information Department's Digital Library

http://www.llnl.gov/tid/Library.html 


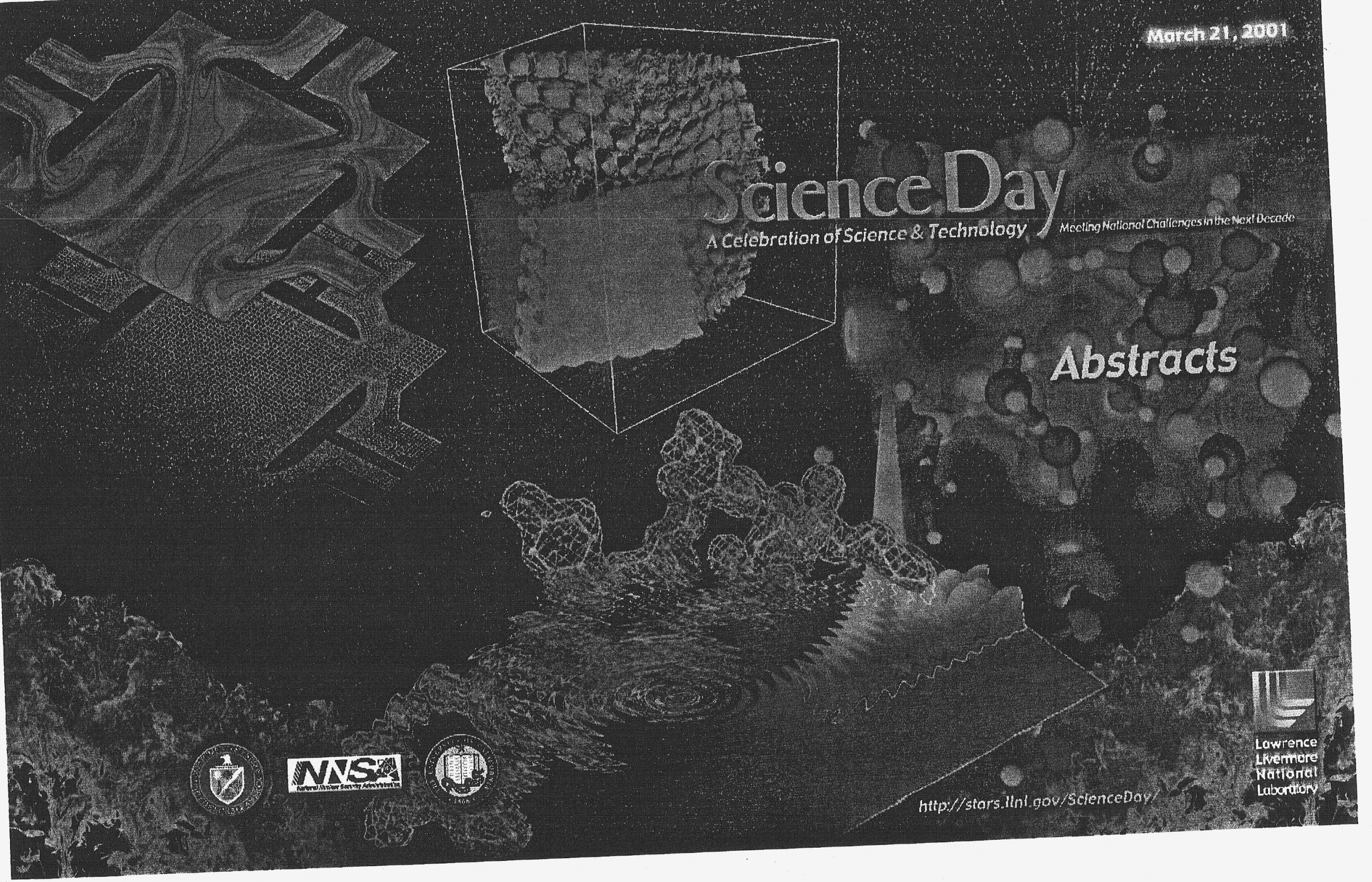




\section{DISCLAIMER}

This document was prepared as an account of work sponsored by an agency of the United States Government. Neither the United States Government nor the University of California nor any of their employees, makes any warranty, express or implied, or assumes any legal liability or responsibility for the accuracy, completeness, or usefulness of any information, apparatus, product, or process disclosed, or represents that its use would not infringe privately owned rights. Reference herein to any specific commercial product, process, or service by trade name, trademark, manufacturer, or otherwise, does not necessarily constitute or imply its endorsement, recommendation, or favoring by the United States Government or the University of California. The views and opinions of authors expressed herein do not necessarily state or reflect those of the United States Government or the University of California, and shall not be used for advertising or product endorsement purposes.

This work was performed under the auspices of the U. S. Department of Energy by the University of California, Lawrence Livermore National Laboratory under Contract No. W-7405-Eng-48.

This report has been reproduced directly from the best available copy.

Available to DOE and DOE contractors from the Office of Scientific and Technical Information P.O. Box 62, Oak Ridge, TN 37831

Prices available from (423) 576-8401

http://apollo.osti.gov/bridge/

Available to the public from the

National Technical Information Service

U.S. Department of Commerce

5285 Port Royal Rd.,

Springfield, VA 22161

http://www.ntis.gov/

OR

Lawrence Livermore National Laboratory

Technical Information Department's Digital Library

http://www.llnl.gov/tid/Library.html

Laboratory Science and Technology Office

P. O. Box 808, L-3

Lawrence Livermore National Laboratory

Livermore, CA 94551 


\section{Lawrence Livermore National Laboratory}

\section{Science Day}

\section{Abstracts}

March 21, 20001

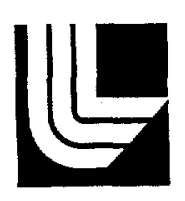

Laboratory Science and Technology Office

P.O. Box 808, L-3

Livermore, CA 94551

Karen Kline, Technical Editor

Paul Harding, Graphic Design

Cover-Daniel Moore 


\section{Contents}

Presentation Abstracts

From the Supercomputer to the Grid

Larry Smarr

Terascal Turbulence: Simulation of Scale Interactions in

Richfmyer-Meshkov Mixing

William Dannevik

Computational Materials Science at the Terascale: Toward Predicting Materials Performance and Aging

Tomas Diaz de la Rubia

Scaling Astrophysics into the Laboratory

Jave Kane

Simulation: Changing the Nature of Scientific Discovery

David Cooper

Quantum Simulations of Condensed Matter Systems

Giulia Galli

Computational Biology

Michael Colvin

Pushing the Envelope of Global Climate Simulation

Starley Thompson

Application of Large-Scale Computer Simulations for Understanding Earthquake

Phenomena

$\hat{\emptyset}$

David McCallen

Poster Abstracts

Activation of the Mercury Laser: A Diode-Pumped Solid-State Laser Driver for Inertial Fusion

A. J. Bayramian

Adaptive Optics

J. M. Brase

Advanced Technology Kill Vehicle

A. G. Ledebuhr, L. G. Ng, E. D. English

Application of Carbon Nanotube-Based Atomic Force Microscopy to

Proteomics and Biological Forensics

A. Noy 
Atmospheric Dispersion Science for Emergency Response

D. Ermak

Bidrectional Scatter Diagnostics Quantifies Scatter Loss of NIF Optics

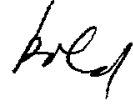

Fluórescence Imaging as a Nondestructive Technique to Identify $3-\omega$ bamage

Precursors on NIF Final Optics

R. Fluck and M. C. Nostrand

Chemical Agent Negation for Theater Missile Defense

G. Nakafuji and R. M. Greenman

Computational Modeling in Laser Medicine

R. A. London

Computer Modeling of a Fusion Plasma

B. I. Cohen

A Cytogenic Signature of PhIP-Induced Mammary Carcinomas in Rats

A. T. Christian and J. D. Tucker

Deep Subsurface Imaging in Tissues Using the Spectral- and PolarizationDifference Imaging Technique

S. G. Demos, M. Staggs, and H. B. Radousky

Designer Diamond Anvil for Advanced High-Pressure Experiments

S. T. Weir, J. Akella, and C. Ruddle

Developing DNA Signatures for Pathogen Detection

G. Andersen, L. Radnedge, and T. Slezak

Development and Applications of a Saturated Table-Top X-Ray Laser

J. Nilsen and J. Dunn

Direct Carbon Conversion: Efficient Systems for Conversion of Fossil Fuels in a Carbon-Managed Economy

N. Cerepy, J. F. Cooper, and R. Krueger

EIGER

K. Mish and R. Sharpe

Environmental and Biomedical Research in the Center for Accelerator Mass Spectrometry

G. Bench et al.

Experimental Geophysics Applied to National Needs

B. P. Bonner

Extreme Ultraviolet Lithography

D. Sweeney

Glucose Sensor

S. Lane 
Handheld Advanced Nucleic Acid Analyzer

R. P. Koopman and S. Nasarabadi

Hydrogen at Extreme Conditions: Building Jupiter in the Laboratory

15

N. Holmes and G. Collins

Isotope Hydrology for Water Resources Management

G. B. Hudson and J. E. Moran

LLNL-Home to the World's Fastest Computer

M. Seager

Matrix-Free Identification of Bacillus Spore Species Using Infrared Laser Desorption and Time of-Flight Mass Spectrometry

J. Ullom, S. Labov, and K. C. Langry

Microfabricated Multifrequency Particle Impedance Characterization System

P. Krulevitch et al.

Modeling Complex Protein Structures

$M$. Tehlen and $C$. Venclovas

New Novel Materials at High Pressures and Temperatures

C-S. Yoo

NUFT Simulations of Subsurface Reactive Flow and Transport

J. J. Nitao

PEREGRINE

C. Hartmann-Siantar

Post-Doctoral Research in NIF Programs

A. Bullock et al.

Progress in Indirect-Drive Inertial Confinement Fusion Experiments

O.L. Landen

Protecting Information Networks

R. R. Burleson

Research and Advanced Tools for Evaluation of Global Climate Models

K. E. Taylor and G. L. Potter

Scalable Algorithms and Software Framework Enable Large-Scale Scientific

Simulations

R. Falgout et al.

The Search for Dark-Matter Axions

\footnotetext{
$K$. van Bibber and D. Kinion

A Single Molecule Study of DNA-Protein Interactions
}

L. Brewer, S. Corzett, and R. Balhorn 
The Spheromak Path to Fusion

D.N. Hill and the SSPX Team

STARS-Science and Technology Awards and Recognition System

P. Harris

Surface-Attached Interlocking Molecules

G. Fox and ArVance

Surveying the Outer Solar System with Robotic Telescopes

S. Marshall, K. Cook, and R. Poratta

Synthesis of Nanocrystals with Tunable Sizes and Properties

L. N. Dinh and M. Balooch

Technology for Fissile Material Storage and Warhead Dismantlement

Transparency

J. F. Morgan and J. Luke

Terascale Browser: Interactive Exploration of Large Data

S. Uselton

The Virtual Valley: An Integrative Tool for Environmental Research, Education, Assessment, and Planning

W. P. Dannevik and D. A. Rotman 


\section{Presentation Abstracts}




\section{Plenary Talk: From the Supercomputer to the Grid}

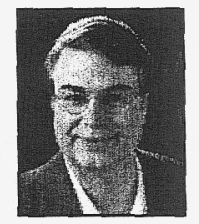

Dr. Larry Smarr

Director, California Institute for Telecommunications and Information Technology Professor, Computer Science and Engineering, University of California, San Diego

\begin{abstract}
In the 25 years since I first came to the Labs, supercomputers have increased in speed nearly one million times, allowing for simulations of enormous complexity. The National Science Foundation Supercomputer Centers, cloned from supercomputers at LLNL and LANL, brought this powerful capability for simulation to the university research community, in the process catalyzing the Internet, the World Wide $W e b$, and scientific visualization. In the last five years, a new concept has arisen as a superset of all this, called the Grid, which adds scientific instruments, sensors, and vast, distributed data stores. This fully distributed Grid will enable future science and engineering. With the rapid extension of the Internet throughout the physical world via wireless technologies, we are rapidly approaching a new regime in which computational power is balanced with extensive SensorNets that are capable of determining the state of the system being simulated.

I will review some examples from weather, environment, transportation, and biology research. Many of the large science projects that the National Science Foundation is planning for the next decade will require such data-intensive, persistent, cyber-Grid infrastructure. The tightly coupled, high-performance Grid is surrounded with a storage and computational power millions of times larger than that contained in a desktop computer; this power comes rom the interconnection of the world's PCs into "megacomputers." The newly created California Institute for Telecommunications and Information Technology was set up to explore the emerging planetary Grid infrastructure and the applications it can support.
\end{abstract}

\section{Biography}

Dr. Larry Smarr is a pioneer in prototyping a national information infrastructure to support academic research, governmental functions, and industrial competitiveness. In 1985, Dr. Smarr became the founding Director of the National Center for Supercomputing Applications (NCSA) at the University of Illinois at Urbana-Champaign (UIUC). In 1997, he also became the founding Director of the National Computational Science Alliance, comprised of over fifty universities, government labs, and corporations linked with NCSA in a national-scale virtual enterprise to prototype the information infrastructure of the twenty-first century. Most recently, Dr. Smarr became the founding Director of the California Institute for Telecommunications and Information Technology, which spans the Universities of California at San Diego and Irvine.

Dr. Smarr received his Ph.D. from the University of Texas at Austin and conducted observational, theoretical, and computational based astrophysical sciences research for fifteen years before becoming Director of NCSA. He is a member of the National Academy of Engineering and a Fellow of the American Physical Society and the American Academy of Arts and Sciences. In 1990 he received the Franklin Institute's Delmer S. Fahrney Gold Medal for Leadership in Science or Technology. Dr. Smarr is a member of the President's Information Technology Advisory Committee. 


$$
\frac{P_{a} E^{2}}{\text { But }}
$$




\section{Terascale Turbulence: Simulations of Scale Interaction in Richtmyer-Meshkov Mixing}

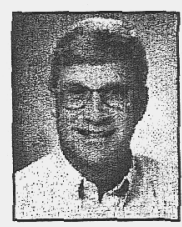

\author{
William P. Dannevik \\ Deputy Associate Director for Science and \\ Technology \\ Energy and Environment Directorate
}

One of the hallmarks of strongly turbulent flows is the very wide range of spatial scales that are dynamically active. Such flows are strongly nonlinear; a predictive understanding of their mixing properties remains one of the outstanding unsolved problems of classical physics. Terascale simulation is a powerful tool for numerical exploration of the behavior of these flows. When combined with complementary laboratory experiments, this approach will lead to better parameterizations of the effects of turbulence in applications such as combustion, aerodynamics, geofluid mechanics, and astrophysics.

Recently, a team* of computational physicists and computer scientists drawn from LLNL, academia, and industry undertook a very highresolution three-dimensional simulation of the turbulent mixing that occurs when the interface between two compressible gases with different mass densities is accelerated by a shock wave (the Richtmyer-Meshkov problem). The simulation was designed to mimic experiments performed at the California Institute of Technology gas dynamics laboratory shock tube. Quantities of interest in these experiments include the rate of growth of thickness of the mixed gas layer, the size distribution of density heterogeneities (eddies), the angular distribution of statistical properties such as eddy correlation lengths, and the partitioning of energy between the shock wave and the mean and fluctuating momentum fields. These are functions of the initial shock strength, the gas density ratio and thermodynamic properties, the geometry of confinement devices (shock tube and gas separation membrane), and other control parameters.

Computations were carried out on several thousand processors of the ASCI Blue SST system. This is a platform with peak throughput of about $4 \mathrm{TF}$, configured as three sectors, each with several hundred four-processor nodes. The algorithm for Euler's equation was based on a directionally split high-order Godunov method (Lagrangian advance

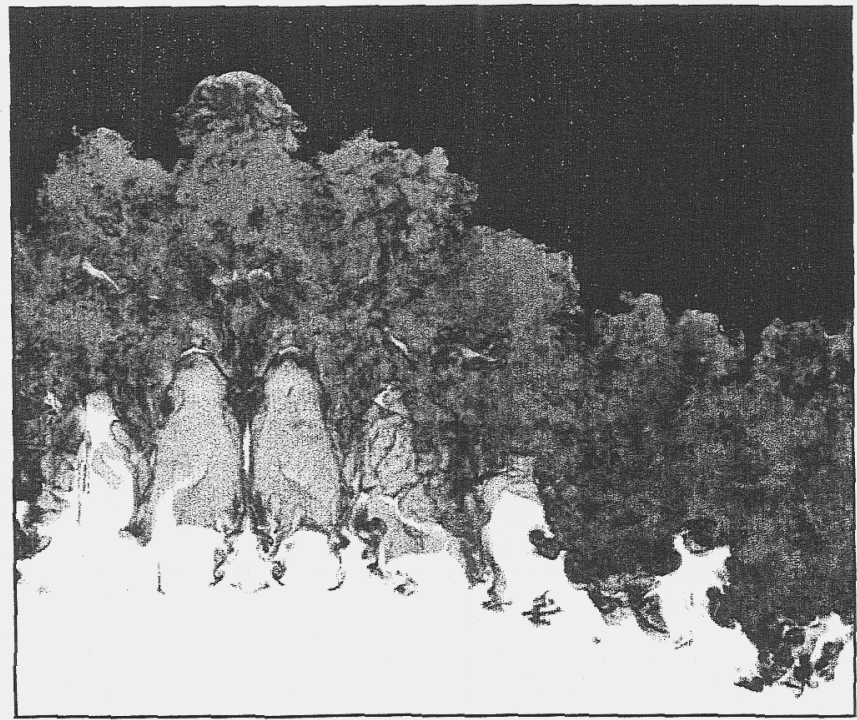

Spatial distribution of entropy from an 8-billion-zone simulation of Richtmyer-Meshkov instability and mixing.

followed by Eulerian remap), parallelized via threedimensional domain decomposition using messagepassing interface (MPI) (internode) and posix threads (intranode). Spatial discretization was typically on the order of ten billion zones. The duration of simulated time corresponded to about ten soundcrossing times for the computational domain (on the order of 20,000 timesteps).

These simulations generate enormous volumes of data. Data exploration has been greatly facilitated by advanced visualization systems under development both at the University of Minnesota and at Livermore. Preliminary analysis of the simulations indicate: (1) time-development of an inertial subrange with Kolmogorov scaling, (2) mixed layer growth rates consistent with the experimental data, (3) apparent convergence of solutions with respect to spatial resolution, (4) a significant impact of the initial curvature of the membrane separating the two gases on the growth rate of large mixing structures, and (5) important qualitative differences in flow properties when compared with two-dimensional simulations with the same control parameters.

This work was awarded the 1999 Gordon Bell Prize for overall performance in a scientific or engineering supercomputing application.

*R. Cohen, B. Curtis, W. Dannevik, A. Dimits, M. Duchaineau, D. Eliason, A. Mirin, and D. Schikore (Lawrence Livermore National Laboratory);

*S. Anderson, D. Porter, and P. Woodward (University of Minnesota);

*L. Shieh and S. White (IBM Corporation) 


\section{Computational Materials Science at the Terascale: Toward Predicting Materials Performance and Aging through Experimentally Validated Multiscale Modeling}

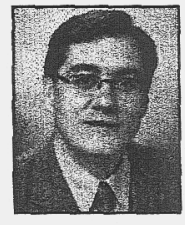

Tomas Diaz De La Rubia

Materials Program Leader for NIF

Chemistry and Materials Science Directorate

Predicting the properties and performance of materials from fundamental physical principles has been a beckoning, yet elusive goal. In recent years, the possibility of achieving this goal has become a reality due to the advent of very large, massively parallel computers capable of doing trillions of operations per second, together with advances in the first-principles description of the interatomic forces that govern materials. This talk describes the application of advanced computational materials science tools to describe the behavior of materials across many length and time scales. A coordinated plan of experimental validation is critical to the success of this effort. Therefore, the presentation provides

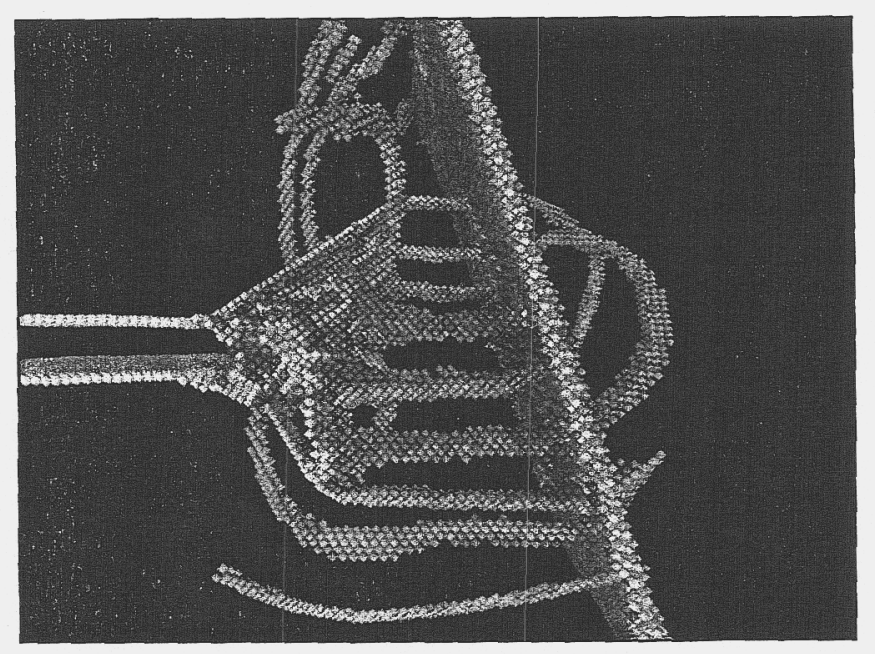

One-billion atom molecular dynamics simulation of dislocations being emitted from a crack tip and interacting with a grain boundary in an fcc metal (courtesy of Farid Abraham). examples of the crucial role experiments play in validating and guiding the computations.

The talk focuses on two topics. First, we describe how a combination of ab initio quantum mechanics calculations and kinetic Monte Carlo simulations can be used to predict the behavior of dopants in semiconductors. ${ }^{1}$ Experiments were carried out in collaboration with Intel and Applied Materials corporations, and the calculations were shown to be in excellent agreement with those experiments. Armed with a validated multiscale model for semiconductor doping, we further explored ways to advance future technology generations. The calculations suggest novel ways to fool a semiconductor lattice into accepting more dopants than the equilibrium thermodynamic solid solubility would suggest, thereby potentially overcoming some of the physics limits to semiconductor manufacturing scaling expected in the next five to ten years. ${ }^{2}$ Experiments are currently underway at Harvard and Bell Laboratories to test the results of the theory.

In the second part, we focus on a problem that has befuddled the materials science community over the last 30 years. Experimental evidence suggests that face-centered cubic (fcc) metals undergo strain localization and hardening when exposed to irradiation environments. However, no satisfactory explanation of this behavior has ever been proposed. We show how the application of largescale ( $>100 \mathrm{M}$ atoms) molecular dynamics simulations, together with three-dimensional dislocation dynamics models describe inhomogeneous deformation of materials, and the localization of plastic flow into 100-200-nm bands in metals exposed to high radiation environments (see Figure). ${ }^{3}$ Our simulations describe, at the atomic scale, the detail mechanism of the interaction between dislocations and radiation-induced defects. These calculations were later validated by in situ transmission electron microscopy. The combination of the experimentally validated atomistic insight and the microscale dislocation dynamics model provide a clear and concise explanation of this long-standing puzzle in materials science. ${ }^{3}$

\section{References}

1Sadigh, B., T. Lenosky, S. Theiss, M.J. Caturla and T. Diaz de la Rubia, Physical Review Letters 83 (21), $4341-4$ (1999).

${ }^{2}$ Sadigh, B.,T. Lenoskym S. Theiss, M. Giles, M. Foad and T. Diaz de la Rubia, submitted to Science, Jan. 2001.

${ }^{3}$ Diaz de la Rubia, T., H. Zbib, B. Wirth, T. Kraishi, M.J. Caturla and M. Victoria, Nature, 408, 871 (2000). 


\section{Scaling Astrophysics into the Laboratory}

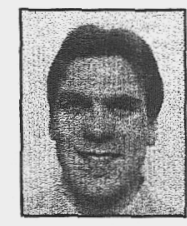

\section{Jave Kane}

Postdoctoral Research Associate

Institute for Laser Science and Applicatons University Relations Program

Astrophysics has traditionally been pursued by astronomers at observatories and by theorists using computers. What's often missing is the ability to quantitatively test theories and computer models with controlled experiments. Intense lasers are now being used to recreate aspects of astrophysical phenomena in the laboratory, allowing scientists to perform quantitative tests. Laser experiments are being developed to aid our understanding in a number of areas, including supernovae, molecular clouds, supernova remnants, radiative jets, and gamma-ray bursts. However, it is necessary to show that the physics in each lab-size experiment can be scaled to the appropriate astronomical-size setting. The talk briefly surveys work in laser astrophysics and focuses on two areas: supernovae and the Eagle Nebula.

Mixing between multiple layers of fluid in divergent geometry appears to be critical in supernovae - the explosion of massive stars, such as the famous SN 1987A. At LLNL's Nova laser and at the Omega laser at the University of Rochester, an increasingly sophisticated series of supernovarelevant targets were shot and the means for scaling from these miniature experiments to stellar dimensions were rigorously described. The experiments were simulated with a widely used astrophysical code, thus testing the modeling tool with relevant data from the lab. The results appear to support a growing consensus that traditional models of supernovae are inadequate to explain observations of these events.

Mixing is also implicated in a long-standing mystery, the towering "Pillars of Creation" of the Eagle Nebula (see Figure). Recently the Hubble Space Telescope and other instruments have been used to measure detailed properties of the Pillars. Fifty years ago, astrophysicists theorized that the
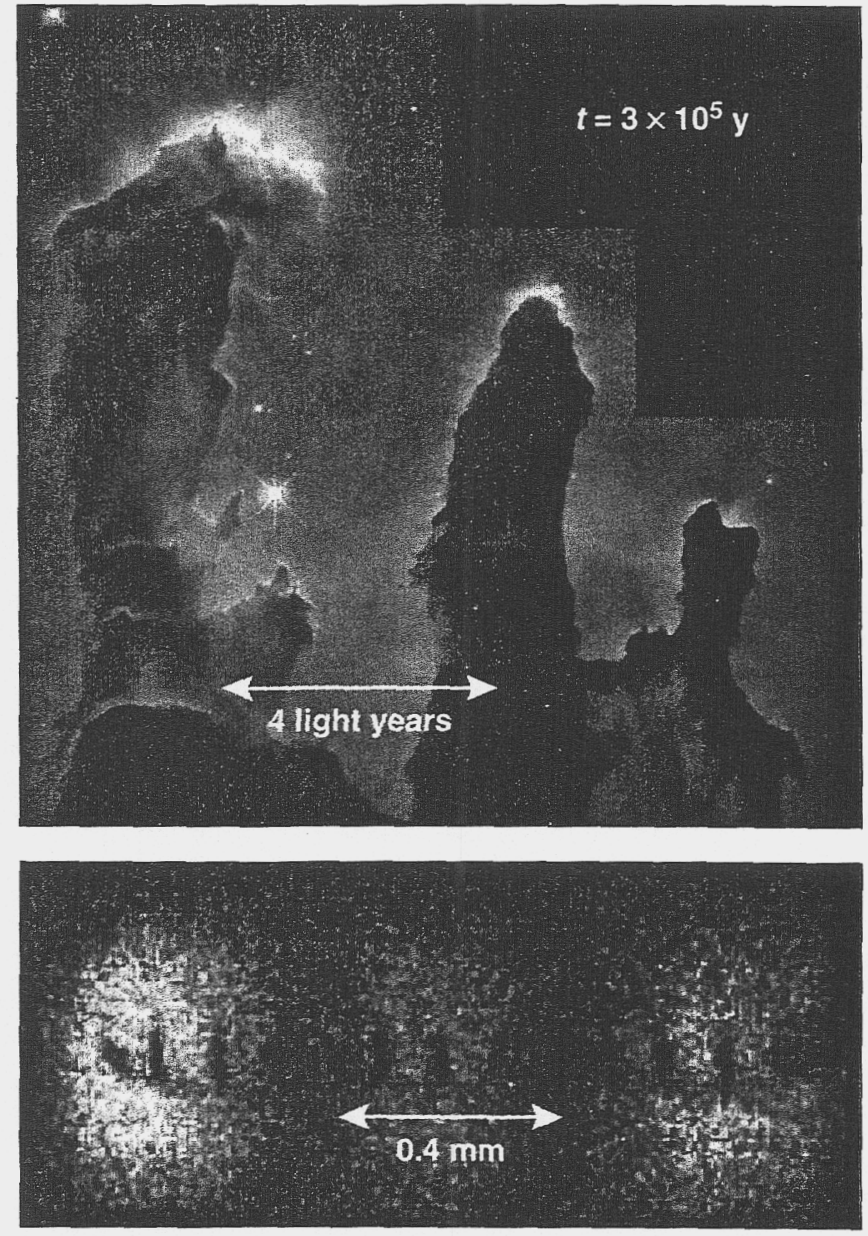

Top: the "Pillars of Creation" in the Eagle Nebula [Hester, J. J., et al., Astronomical Journal 111, 2349 (1996)]. Bottom: miniature pillars in a laser astrophysics experiment [Remington, B. A., et all Physics of Fluids B 4, 967 (1992)].

Pillars are produced by the rocket-like push of material boiled off the Nebula by ultraviolet radiation from bright nearby stars. Through computer simulations of the Eagle Nebula, it was found that this 50-year old model reproduces the recent detailed measurements, if two important modifications are made. The next step will be to test the revised model in the lab by illuminating miniature versions of the Eagle Nebula with intense lasers. As a first step, the code used to successfully model the Eagle Nebula is being tested against data from classic experiments performed at the Nova laser. 


\section{Simulation: Changing the Nature of Scientific Discovery}

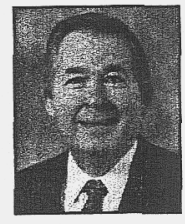

\section{David M. Cooper}

Associate Director for Computation and Chief Information Officer

Modeling and simulation are increasingly important in many of the Department of Energy's (DOE's) programs. For example, large-scale simulation is now playing an enabling role in the DOE/National Nuclear Security Agency's (NNSA's) Stockpile Stewardship Program (SSP). The challenge facing the SSP is to maintain confidence in a smaller nuclear stockpile in the absence of underground nuclear testing. Large-scale simulation provides the key to meeting this challenge. Similar challenges face the DOE Office of Science's new Scientific Discovery through Advanced Computing (SciDAC) initiative, which seeks to advance scientific discovery through the use of terascale simulation.

High-performance computers-supercomputers-will provide this new capability and serve as the platforms for the integration of experimental data. In support of NNSA mission needs, the Accelerated Strategic Computing Initiative (ASCI) was created to accelerate the development and deployment of supercomputers far beyond what might have been achieved by simply accepting the status quo or tracking market availability.

High-performance simulation, however, requires more than just a very large, fast supercomputer. It requires a balanced computing environment consisting of high-speed networks and storage and data analysis, including scientific visualization. It also requires algorithm research focused on developing algorithms that are scaleable and efficient. Programming techniques capable of providing simultaneous and efficient use of thousands of processors are essential. Finally, high-performance simulation requires a state-of-the-art facility capable of providing the floor space and power to house and operate massive terascale computers.

The recent successes in simulating, for the first time in three dimensions, the primary and secondary components of an ignited nuclear weapon attest to the unprecedented progress of the ASCI program. These accomplishments were based on the successes of other elements of the ASCI program: scaleable algorithms, programming techniques for thousands of processors, and unparalleled visualization capabilities. LLNL has leveraged the ASCI investment in simulation capabilities along with an institutional investment to support multiple programs and institutional users to create a largescale simulation program that is unique in scientific circles. This large-scale simulation capability now plays a central role in almost every LLNL scientific program. Furthermore, based on the success of the ASCI and other simulation programs (at LLNL and elsewhere), it is safe to conclude that simulation is emerging as a partner with theory and experiment in the realm of scientific discovery.

This presentation will describe the current terascale computing environment, including the unprecedented levels of both classified and unclassified computing capability at LLNL. The talk will discuss the strategy to acquire, develop, and use this unique simulation capability, along with the plans for the future. LLNL's strategic partnerships with the computing industry will also be described.

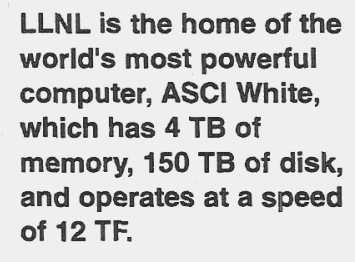

LLNL is the home of the world's most powerful memory, 150 TB of disk, and operates at a speed of 12 TF.

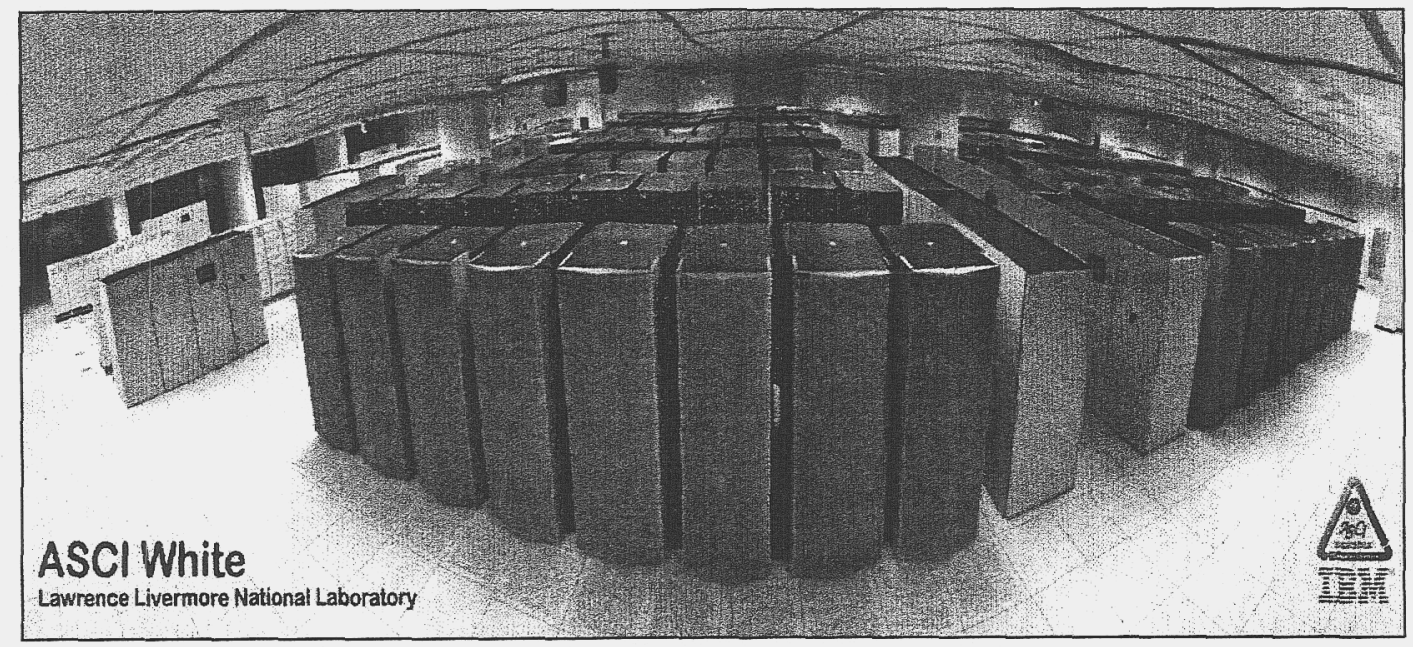




\section{Quantum Simulations of Condensed Matter Systems}

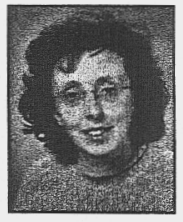

\author{
Giulia A. Galli
}

Quantum Simulation Group Leader Physics and Advanced Technologies Directorate

Quantum simulations-simulations at the microscopic level using the laws of quantum mechanics - provide a fully predictive approach to the study of condensed matter systems and a general framework that can be applied to problems in different fields of science. As P. A. M. Dirac stated in 1929, after the theoretical foundations of quantum mechanics were laid out: "The underlying physical laws necessary for the mathematical theory of the [...] whole of chemistry are thus completely known, and the difficulty is only that the exact application of these laws leads to equations much too complicated to be soluble."

In the 1960s, high-speed digital computers came into use for solving quantum mechanical equations. In particular, quantum chemistry emerged as a new branch of chemistry, and key theoretical developments (e.g., density functional theory) led to simplified mathematical description of chemical bonds. Since then, these methodologies have been extensively used in physics and chemistry to improve our fundamental understanding of materials. The 1998 Nobel prize in chemistry, awarded to W. Kohn for his development of density functional theories and to J. Pople for computational methods in quantum chemistry, clearly shows the importance and impact of computational quantum mechanics.

In this talk I will present recent results obtained at LLNL using quantum molecular dynamics. In particular, I will briefly discuss how the physical properties of water (see Figure) and hydrogen are modified at high temperature and pressure, the interaction of some organic molecules with water, and how structural and electronic properties of selected semiconductors are modified at the nanoscale.*

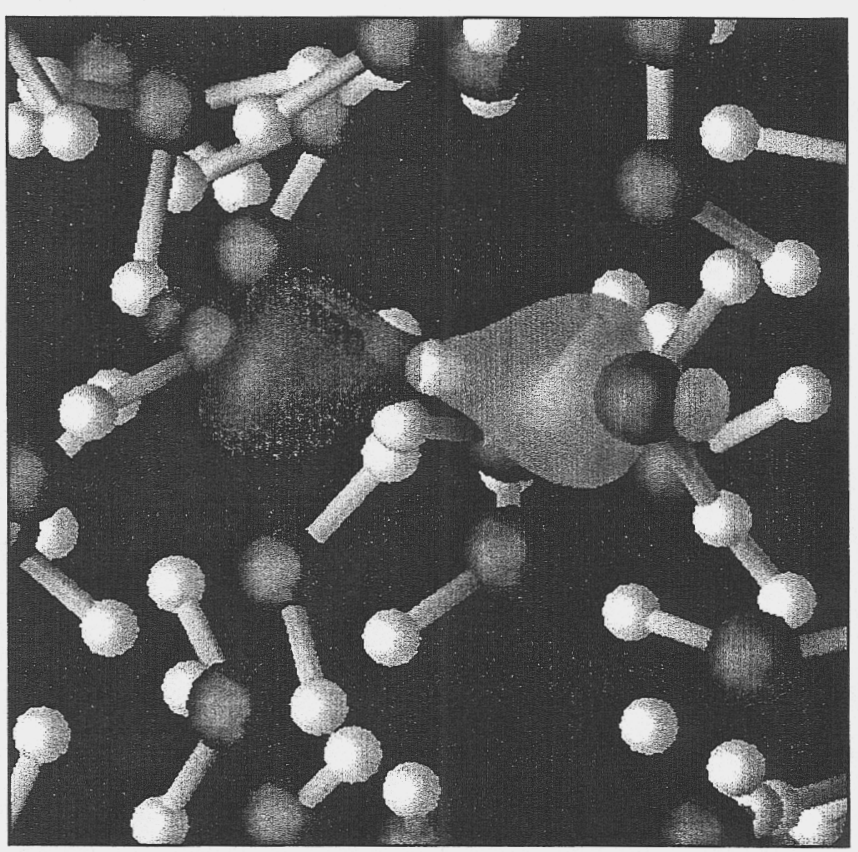

This picture shows a snapshot of an ab initio simulation of water at $30 \mathrm{GPa}$ (red and white spheres represent oxygen and hydrogen atoms, respectively). A proton transfer occuring under pressure is represented by localized orbitals (blue and green surfaces) on two oxygen atoms.

The presentation aims at illustrating state-ofthe-art investigations of both physical and chemical properties of condensed matter systems, and at pointing out the important role of quantum simulations in the study of complex systems. Ab initio simulations can give predictions when experiments are not possible or are difficult to carry out (some specific examples will be discussed); they can give access to information not directly available to experiment (e.g., the detailed microscopic structure at the atomic level of a liquid or a glass); and they can guide, complement, and help interpret experiments. In short, quantum simulations provide very useful virtual laboratories that complement real laboratories and mathematical theories.

* Work done in collaboration with R.Q. Hood, J. Grossman, F. Gygi, E. Schwegler, A. Williamson, L. Pizzagalli, and J. Klepeis. 


\section{Computational Biology}

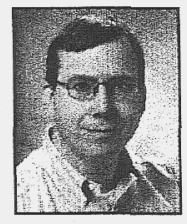

The emerging explanation of biology in terms of its underlying chemical processes is one of the great triumphs of science and holds vast potential for improving human well-being. One consequence of this fundamental understanding is the growing role of computational simulations in biological research. Three years ago LLNL began a multidirectorate collaboration to use advanced computational methods at the forefront of state-of-the-art biological simulation and to apply these methods to solve biological problems.

Modeling biology at the atomic level presents many challenges. First, biochemical reactions involve large chemical systems with very subtle reaction energetics that often operate far from equilibrium. Furthermore, because we seldom know all of the relevant chemical details of a biological reaction, significant care is required to reformulate a biological hypothesis in a form that can be conclusively addressed by molecular simulations. Despite these challenges, simulations can provide new insight for a growing number of biochemical processes, leading to new drugs and therapies, as well as a more fundamental knowledge of the chemical basis for life.

This talk presents a number of computational methods for biological simulation and describes the application of these methods. At the most empirical level, we use "homology-based" prediction methods to compute the three-dimensional shape of proteins based on pattern-matching with homologous, experi-

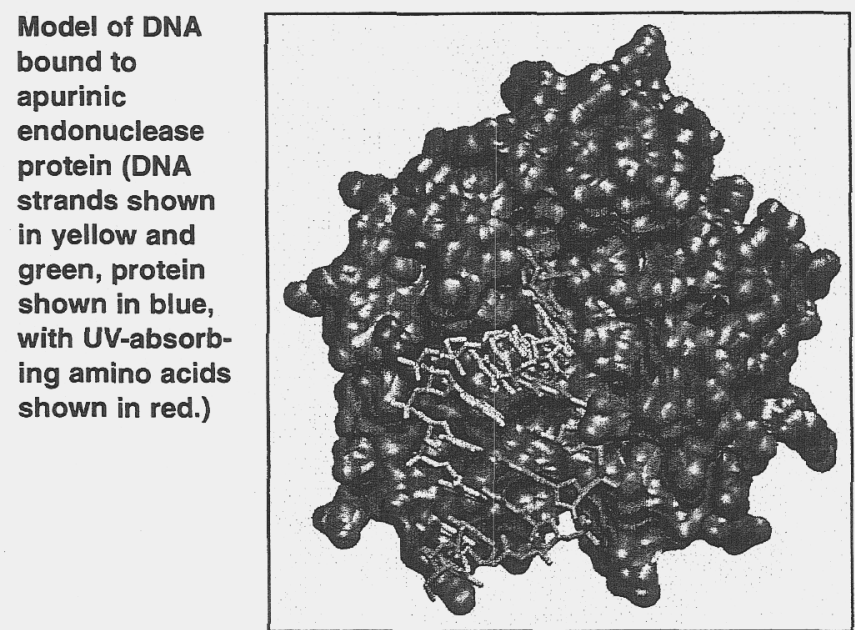

mental protein structures. We are also using classical molecular dynamics methods that use empirical "ball-and-spring" force fields to model macromolecular motions, and "docking" methods to rapidly screen for small molecules that will bind to specific protein sites. We are also using ab initio quantum chemical methods to accurately calculate static chemical properties of biomolecules. Finally, we are collaborating with researchers in the Physics and Computations Directorates to apply newly developed first-principles molecular dynamics methods, in which accurate quantum mechanical force fields are used to simulate the atomic motion in biochemical processes.

To date we have applied this range of simulation methods to provide insights into a variety of biological questions, with a focus on DNA and the mechanisms of DNA damage and repair. We have studied the metabolic activation reactions of mutagenic DNA-binding compounds that form when foods are cooked at high temperatures, and have identified correlations between the chemical properties of these compounds and their toxicity. ${ }^{1}$ We also have studied the activation and DNA binding of a widely used class of anticancer drugs. ${ }^{2}$ We simulated the structure and dynamics of chemically damaged DNA and the enzymes that repair this form of damage ${ }^{3}$ and the energetics of DNA base-pairing. ${ }^{4}$ We have used protein prediction methods to study the enzymes that activate the food mutagens and proteins that attach to DNA. ${ }^{5}$ Additionally, we applied docking methods to identify inhibitors of DNA repair enzymes and chemicals that bind protein toxins. ${ }^{6}$

\section{References}

${ }^{1}$ Colvin, M.E., F.T. Hatch and J.S. Felton, “Chemical and biological factors affecting mutagen potency," Mutation Research, 400, 479-492 (1998)

${ }^{2}$ Colvin, M.E., J.C. Sasaki and N.L. Tran, “Chemical factors in the action of phosphoramidic mustard alkylating anticancer drugs: roles for computational chemistry," Current Pharmaceutical Design, 5, 645-663 (1999).

${ }^{3}$ Barsky, D., N. Foloppe, S. Ahmadia, D.M. Wilson and A.D. MacKerell, "New insights into the structure of abasic DNA from molecular dynamics simulations," Nucleic Acids Research, 28, 2613-2626 (2000).

${ }^{4}$ Barsky, D. and M.E. Colvin, "Guanine-cytosine base pairs in parallel-stranded DNA: An ab initio study of the keto-amino wobble pair versus the enol-imino minor tautomer pair," Journal of Physical Chernistry B, 104, 8570-8576 (2000).

${ }^{5}$ Thelen, M.P., C. Venclovas and K. Fidelis, "A sliding clamp model for the Rad1 family of cell cycle checkpoint proteins," Cell, 96, 769-70 (1999).

${ }^{6}$ Lightstone, F.C., M.C. Prieto, A.K. Singh, M.C. Piqueras, R.M. Whittal, M.S. Knapp, R. Balhorn and D.C. Roe, "The identification of novel small molecule ligands that bind to tetanus toxin," Chemical Research in Toxicology, 13, 356-362 (2000). 


\section{Pushing the Envelope of Global Climate Simulation}

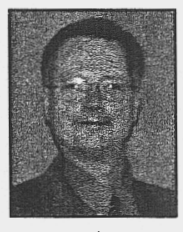

Starley L. Thompson

Scientist, Climate and Carbon Cycle Modeling Group

Energy and Environment Directorate

Earth's climate is changing. Compelling evidence indicates that human activity is playing a substantial role in global climate change, but just how large a role is still uncertain. Separating natural climate variability from any changes produced by fossil-fuel burning is a challenging research problem set within a broader context of economic and political debate. One of the goals of climate simulation is to provide a firmer scientific foundation for decision makers so that science can inform the debate, not lag behind it.

The Department of Energy has a history of supporting climate modeling, particularly in advancing simulation technology on highperformance computers. LLNL has been part of this effort and has pursued research to improve understanding of Earth's complex climate system and to reduce uncertainties in climate predictions.

The talk will survey three areas of current LLNL computational climate science:

1. Ocean Carbon Sequestration

This modeling research investigates the potential to place fossil-fuel carbon dioxide directly into the oceans. Ocean sequestration would bypass the atmosphere and reduce climate impacts.

2. Integrated Climate and Carbon Simulation Credible simulations of the entire climate system need to predict the time-evolving concentration of atmospheric carbon dioxide and allow for feedback between climate and the carbon cycle. Work is progressing at LLNL to couple together models of the atmosphere, ocean, land biosphere and ocean
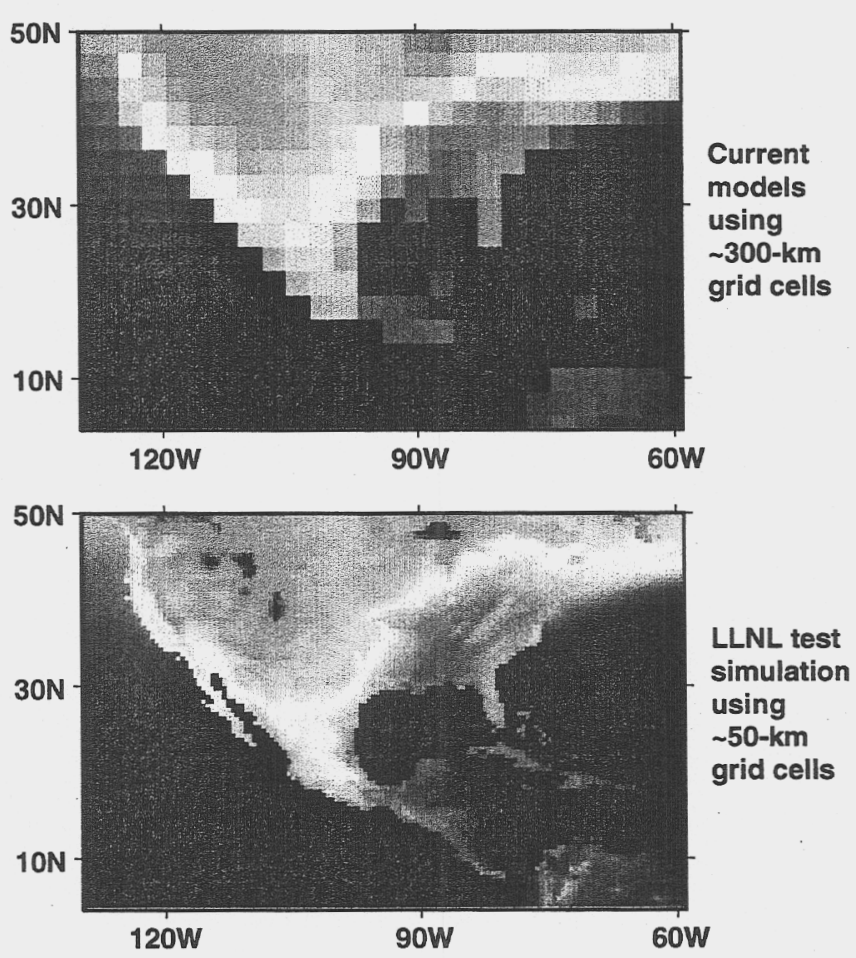

An example of North American surface temperature simulated at a typical climate model resolution in use today (top) and results from a test simulation done at LLNL using the highest resolution yet attempted in a global climate model (bottom).

chemistry to develop a comprehensive predictive capability. 1

3. High-Resolution Global Atmospheric Simulation Current operational climate models cannot resolve features smaller than about $250-\mathrm{km}$ wide. Future models must improve on this to provide meaningful regional-scale information. LLNL has recently started an effort to produce the highest resolution climate simulation yet attempted-an experimental global run at a 50-km resolution.

\section{Reference}

${ }^{1}$ Caldeira, K., and P.B. Duffy, "The role of the Southern Ocean in uptake and storage of anthropogenic carbon dioxide," Science, 287, $620-622,(2000)$ 


\section{Application of Large-Scale Computer Simulations for Understanding Earthquake Phenomenon}

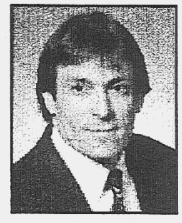

\author{
David McCallen \\ Director, Center for Complex Distributed \\ Systems \\ Engineering Directorate
}

Major earthquakes around the world (e.g. Japan, 1995; Taiwan, 1999; Turkey, 1999; India, 2000, 2001) have demonstrated their potential for massive destruction in densely populated areas. Many locations in the United States are susceptible to such

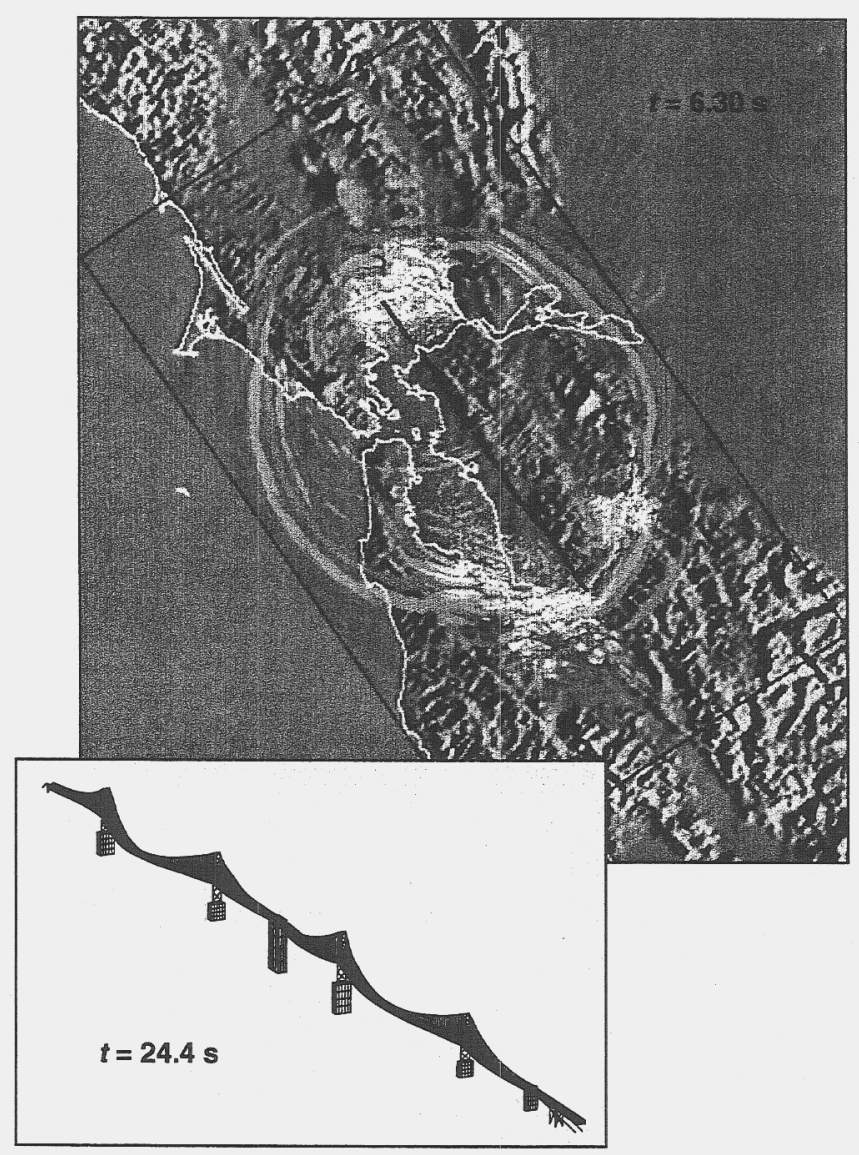

Simulation of seismic wave propagation in the San Francisco Bay Area resulting from a magnitude 7 Hayward Fault earthquake. The inset shows the response of the Bay Bridge to the simulated motions. earthquakes. For example, the San Francisco Bay Area, home to the nation's computer industry in Silicon Valley, is traversed by a number of active and dangerous earthquake faults. Recent scientific studies indicate a high probability that a major Bay Area earthquake will occur within the next 30 years. It is essential that a complete understanding of earthquake phenomena be developed in order to economically construct safe buildings and transportation systems.

Field measurements of ground motions and structural response in actual earthquakes have illustrated the complex variability of earthquake ground motions and the complicated manner in which structures vibrate during earthquakes. A significant amount of the available information regarding earthquake phenomena has been obtained by collecting data from actual earthquakes. For example, recent earthquakes in California (Loma Prieta, 1989 and Northridge, 1994) have highlighted the structural deficiencies in older structures, and have indicated how certain site and geologic conditions may result in locally intense ground shaking. Yet, much remains to be learned about earthquake phenomena. Particularly pressing is the need to accurately predict the ground motions that can be expected at a site and appropriately design major structures to achieve maximum earthquake resistance. Waiting to gather data from future earthquakes in order to assess structural performance is not a desirable or acceptable alternative.

Emerging high-performance computer capabilities offer the potential for realistic simulations of complex earthquake processes. For the first time, massively parallel computer engines can rigorously simulate the complexities of threedimensional regional seismic wave propagation and nonlinear structural response, including damage and degradation in the structure. Such simulations provide the engineer and the earth scientist with extremely powerful tools for looking into the future to predict how the ground will shake and how a given structure will respond. This talk will present results of recent LLNL largescale computer simulations of seismic wave propagation in the San Francisco Bay Area, and the response of the San Francisco-Oakland Bay Bridge to potential future earthquakes. The talk will highlight the importance of newly identified phenomena such as large ground-displacement pulses that occur near earthquake faults. 


\section{Poster Abstracts}




\section{Activation of the Mercury Laser: A Diode- Pumped Solid-State Laser Driver for Inertial Fusion}

Andy J. Bayramian

NIF Programs Directorate

Initial measurements are reported for the Mercury laser system, a scalable driver for rep-rated highenergy-density physics research. The performance goals include $10 \%$ electrical efficiency at $10 \mathrm{~Hz}$ and $100 \mathrm{~J}$ with a 5 -ns pulse length. This laser is an angularly multiplexed 4-pass gas-cooled amplifier system based on image relaying to minimize wavefront distortion and optical damage risk at the $10-\mathrm{Hz}$ operating point. The efficiency requirements are fulfilled using diode laser pumping of ytterbiumdoped strontium fluorapatite crystals.

\section{Adaptive Optics}

James M. Brase

Physics and Advanced Technologies Directorate

Adaptive optics technology is revolutionizing our capabilities to control light in applications ranging from large astronomical telescopes to high-energy laser systems to human vision. Advances in microelectromechanical systems (MEMS), coupled with new image sensors and quickly advancing computer capabilities, will provide small, inexpensive optical systems that can break through the performance limitations in current systems. These new capabilities will allow us to focus laser beams with unprecedented precision, see the universe at new levels of detail, communicate at high data rates through the atmosphere, and provide human vision at unexplored levels of clarity. LLNL is developing this technology for applications in lasers, communications, remote sensing, and astronomy.

\section{Advanced Technology Kill Vehicle}

Arno G. Ledebuhr and Edward D. English

Physics and AdvancedTechnologies Directorate

Larry G. Ng

Engineering Directorate

Improving on the legacy LLNL technologies from the Brilliant Pebbles space-based interceptor, the Raptor/Talon boost-phase interceptor, and the Clementine Moon Mapping programs in the early 90s, we are further pushing the technology envelope to develop an agile, lightweight, high-performance, advanced-technology kill vehicle (ATKV) to support the current and future national missions in ballistic missile defense and space security and management. Key advances of the ATKV include innovative non- toxic, pumped propulsion; miniaturized sensors and avionics; lightweight structures and components; smart guidance, navigation and control software; and high-fidelity, cost-effect groundtest methodologies.

\section{Application of Carbon Nanotube-Based Atomic Force Microscopy to Proteomics and Biological Forensics}

Aleksandr Noy

University Relations Program

Direct imaging of macromolecules by atomic force microscopy (AFM) presents a very attractive method for determining the structure of biological molecules because it bypasses the need for crystallization. However, until recently the large size of its probes has severely limited the usefulness of AFM. A new generation of probes based on carbon nanotubes has promised a significant increase in the AFM resolution. The unique geometry, and the mechanical and electronic properties of nanotubes are contributing to a probe that is sharp, robust, and has a high aspect ratio. We have developed the capability to fabricate probe tips at LLNL and have applied these probes to image the capsid substructure of a single virus, protein-DNA complexes, and membrane protein assemblies.

\section{Atmospheric Dispersion Science for Emergency Response}

Donald Ermak

Energy and Environment Directorate

The National Atmospheric Release Assessment Center (NARAC), supported by the DOE, includes several powerful operational capabilities. NARAC responds worldwide to emergencies associated with the release of hazardous material into the atmosphere. Research and development efforts include developing and evaluating models; performing field experiments; and integrating models into the operational system, including the collection and storage of global meteorological observations and forecast data, global geographical information, agent transport properties and health effects, and source characteristics for a broad range of releases. We recently completed simulations for the Salt Lake region, coupling from the regional scale, through the urban scale, to the building scale. 


\section{Bidirectional Scatter Diagnostics Quantifies Scatter Loss of NIF Optics}

Regula Fluck

NIF Programs Directorate

Fluorescence Imaging as a Nondestructive

Technique to Identify 3- $\omega$ Damage

Precursors on NIF Final Optics

Michael C. Nostrand

NIF Programs Directorate

The National Ignition Facility (NIF) will incorporate 192 high-intensity beams focused onto an inertial confinement fusion target. The final optics assemblies (FOAs) convert the laser beams from 1.053 to $0.351-\mu \mathrm{m}$ wavelength and focus the beams onto the target. The fluence of ultraviolet light is close to the damage threshold for the FOA optics. Stray radiation outside the small ( $\pm 200 \mu \mathrm{rad})$ acceptance angle of the target may have adverse effects on the system performance: scattered light may interfere with the main beam, resulting in damage or growth of damage at pre-existing damage sites on the FOAs. A bidirectional scatter diagnostic was developed to characterize the transmission and scatter of NIF final optics. By nondestructively identifying prospective damage sites through fluorescence imaging, it may be possible to reduce the incidence of damage in the final optics due to the high-intensity $0.35-\mu \mathrm{m}$ laser so that these damage sites can be mitigated or removed.

\section{Chemical Agent Negation for Theater Missile Defense}

Glen Nakafuji,

Nonproliferation, Arms Control, and International

Security Directorate

Roxana M. Greenman

Engineering Directorate

Collaborator:

Theo Theofanous

University of California, Santa Barbara

Short- and medium-range ballistic missiles carrying chemical-agent warheads represent a lethal threat to ground personnel in a targeted area. Current theater missile defense systems are designed to intercept incoming warheads during their terminal descent. The fate of chemical agents released during and after such an intercept is currently unknown. A mutidirectorate Laboratory team, in collaboration with the University of California at Santa Barbara (UCSB), is pursuing experimental, theoretical, and computational tasks relating to the hydrodynamic breakup of chemical agents during fallout. We are also working on experiments and chemical kinetics modeling to address the possible chemical decomposition of dispersed agents. Our goal is to develop a science-based methodology that can address key data gaps in the missile-lethality knowledge base of the Ballistic Missile Defense Organization (BMDO).

\section{Computational Modeling in Laser Medicine}

Richard A. London

Defense and Nuclear Technologies

Computational modeling can be very useful in medicine for designing new instruments and procedures and for patient-specific treatment planning and physician training. Experimental data is used to improve input data and physical models, leading to a validated model that can be used to optimize system parameters for particular procedures. At LLNL, we have developed the LATIS computer program to model laser-tissue interaction. LATIS simulates the time- and space-dependent processes of laser propagation and the resulting thermal, material, and mechanical response of the tissue. The poster describes applications of LATIS to several projects are described, including thrombolysis, ultra-short-pulse high-precision tissue ablation, tissue welding, treatment for benign prostate hyperplasia, lithotripsy of kidney stones, optical coherence tomography, and photodynamic treatment of arthritis.

\section{Computer Modeling of a Fusion Plasma}

Bruce I. Cohen

Physics and Advanced Technologies Directorate

Progress in the study of plasma physics and controlled fusion has been profoundly influenced by dramatic increases in computing capability. Computational plasma physics has become an equal partner with experiment and traditional theory. This presentation illustrates some of the progress in computer modeling of plasma physics and controlled fusion.

\section{A Cytogenic Signature of PhIP-Induced Mammary Carcinomas in Rats}

Allen T. Christian and James D. Tucker

Biology and Biotechnology Research Program

We have developed a way to link cytogenetic and genomic data using a rat mammary carcinogenesis model and a new microdissection technique. A dietary mutagen/carcinogen, $\mathrm{PhIP}$, which is found in cooked meats, induces tumors in the rat mammary 
gland and has been implicated in the etiology of certain human cancers including breast cancer. We used comparative genomic hybridization (CGH) to examine the DNA in rat mammary carcinomas induced by $\mathrm{PhIP}$, and for comparison, by DMBA, a potent experimental mammary carcinogen. We found a consistent and characteristic pattern of chromosome-region loss in PhIP-induced carcinomas that clearly distinguished them from carcinomas induced by DMBA. To determine which genes in these regions may be involved in PhIP-induced mammary carcinogenesis, we developed a method to characterize and map the expressed genes in the normal rat mammary gland. This technique represents a powerful new way to analyze the response of both known and novel genes to a specific chemical or physical agent.

\section{Deep Subsurface Imaging In Tissues Using The Spectral And Polarization Difference Imaging Technique}

Stavros G. Demos, Michael Staggs, and Harry B. Radousky

University Relations Program

The spectral polarization difference imaging technique (SPDI) is proposed as a new method for deep-subsurface imaging in tissues. This technique utilizes the wavelength dependence of the mean visit depth of photons inside a tissue sample before they emerge in the backscattered direction. Crosspolarized images under different illumination wavelengths are recorded with the exposure time of the CCD camera, appropriately adjusted so that the image information arising from the outer tissue layers is approximately the same. The SPDI-based image is obtained by subtracting normalized images under different illumination wavelengths. Imaging depths of the order of $1 \mathrm{~cm}$ are demonstrated. The improvement of the contrast in the SPDI images is the result of removing a large segment of the image information that is not relevant to the target. The advantage of this technique is that it allows for large imaging depths, which is achieved at the expense of the limited spatial resolution.

\section{Designer Diamond Anvil for Advanced High- Pressure Experiments}

Samuel T. Weir, Jagan Akella, and Chantel Ruddle

Defense and Nuclear Technologies

Collaborators:

Yoghesh K. Vohra and Aaron Catledge

University of Alabama at Birmingham
Diamond anvil cells, important for ultra-highpressure research, are capable of pressurizing small samples to "center-of-the Earth" conditions ( $P=$ 3.6 Mbar or 3.6 million atm). Experiments at these ultra-high pressures are invaluable for expanding our understanding of the fundamental physics of condensed matter, and for explaining how matter transforms from one crystallographic or electronic state to another. To address the need for better experimental diagnostics at ultra-high pressures, we have recently developed an entire suite of new ultrahigh-pressure diagnostic probes that feature diamond-encapsulated microcircuits capable of functioning at multi-Mbar pressures.

\section{Developing DNA Signatures for Pathogen Detection}

Gary Andersen, Lyndsay Radnedge, and Tom Slezak Biology and Biotechnology Research Program

Yersinia pestis, the causative agent of bubonic plague, is very closely related to the enteric pathogen Yersinia pseudotuberculosis, which causes relatively mild gastro-intestinal disease. Interestingly, the difference in DNA sequence of the genomes of the two species differs by less than ten percent. This very small variation in the two DNA sequences (and resulting genes) makes a dramatic difference in the pathogenic effects of the two organisms. We have applied both computation- and laboratory-based methods for identifying the specific regions in the DNA that differentiate the two bacterial species. These different regions are used to develop unique "DNA signatures" for each specific bacterial type. Verified signatures can be incorporated into a variety of detection systems and used to differentiate two genetically very similar organisms.

\section{Development and Applications of a Saturated Table-Top X-Ray Laser}

Joseph Nilsen and James Dunn

Defense and Nuclear Technologies Directorate

With the development of the prepulse technique at LLNL and the advances in short-pulse laser technology, the high-repetition rate, table-top Comet laser can drive saturated nickel-like $x$-ray lasers with wavelengths from 20.3 to $13.9 \mathrm{~nm}$ using less than $10 \mathrm{~J}$ of energy. The Comet laser, which can be fired every $3 \mathrm{~min}$, consists of two beams. The prepulse technique uses the uncompressed 1-J, 600-ps beam to preform and ionize the plasma, followed 700 ps later by the compressed 5-J, 1-ps beam to heat the plasma and achieve lasing. With the Comet laser, we can now pursue applications of $x$-ray lasers, some of which 
were proposed and tested at Nova but never pursued because of the cost and low shot rate. The availability of a table-top $x$-ray laser in conjunction with multilayer $x$-ray optics enables us to extend many of the sophisticated measurement techniques developed for optical lasers into the $\mathrm{x}$-ray region.

\section{Direct Carbon Conversion: Efficient Systems for Conversion of Fossil Fuels in a Carbon- Managed Economy}

Nerine Cherepy, John F. Cooper, and Roger Krueger Chemistry and Materials Science Directorate

What if we were able to double the efficiency of electric power generation from coal, petroleum or natural gas from $40 \%$ to $80 \%$, and thus cut the $\mathrm{CO}_{2}$ output in half? What if we could produce a pure $\mathrm{CO}_{2}$ byproduct that could be directly sequestered in deep geologic reservoirs? What if this process did not involve combustion and associated air pollution? Direct carbon conversion employs a new class of fuel cell that generates electricity from the electrochemical reaction of carbon and atmospheric oxygen. The cell operates at $750-850^{\circ} \mathrm{C}$ using a molten-carbonate salt immobilized in a porous ceramic separator. The carbon/air cell is unique because nearly all of the carbon combustion energy can be converted into electric power. In cell's operating at practical rates, a single pass of carbon into the cell yields $80 \%$ of its energy as electricity. The cell is nonpolluting and only $\mathrm{CO}_{2}$ emerges in a pure form that can be sequestered without additional costs of collection and separation.

\section{EIGER}

Kim Mish and Rob Sharpe

Engineering Directorate

EIGER, a scalable electromagnetics framework that fits within LLNL's national security mission, models frequency-domain electromagnetics. It is an ideal high-fidelity design-and-analysis tool for antennas and other communications equipment used in DOE and DoD programs and in industry. The EIGER development team includes LLNL, Sandia/Albuquerque, the University of Houston, and the U. S. Navy SPAWAR center in San Diego.

\section{Environmental and Biomedical Research in the Center for Accelerator Mass Spectrometry}

Graham Bench, Tom Brown, Bruce Buchholz, Marc Caffee, Karen Dingley, Brian Frantz, Patrick Grant, Tom Guilderson, Michaele Kashgarian, John Knezovich, Carrie Masiello, Ted Ognibene, Gordon Seitz, John Southon, Ken Turteltaub, and John Vogel

University Relations Program and Biology and Biotechnology Research Program The Center for Accelerator Mass Spectrometry (CAMS) at LLNL is the most versatile and productive facility of its kind in the world. The center houses AMS systems that provide exceptionally sensitive approaches for measuring concentrations of specific isotopes (e.g., ${ }^{14} \mathrm{C}$ ) in relatively small $(<1 \mathrm{mg})$ samples and a nuclear microprobe that provides micron-scale resolution of elements in biological materials. The sensitivity and precision of AMS has lead to a variety of applications in environmental and biological research, much of which is conducted in collaboration with university researchers. For example, ${ }^{14} \mathrm{C}$-AMS has been successfully used to assess the history of earthquakes and to define the distribution and transformation of chemicals in humans. In this poster, several recent applications will be highlighted.

\section{Experimental Geophysics Applied to National Needs}

Brian P. Bonner

Energy and Environment Directorate

Experimental geophysics at LLNL is applied to national needs in national security, environment, and energy. Our specialized experimental apparatus can simulate conditions in materials and/or in the earth at temperatures ranging from 77 to $2000 \mathrm{~K}$ and at pressures ranging from 1 to about 1 million atm, using samples ranging in size from a few microns to about a meter. For national security, the physical properties of metals and special nuclear materials, and phase transitions in high explosives at high pressure are being studied using diamond anvil cells and other high-pressure apparatus. Environmental problems being studied include measurement of soil properties at low pressures for environmental cleanup applications, corrosion of materials under unusual conditions, reactive transport in fractures, and electrical resistivity of rocks at in-situ conditions. Energy issues under experiment include deformation of methane hydrate, resistivity of fluids while boiling, geophysicial properties needed for subsurface imaging, and data required for nuclear waste repository designs. 


\section{Extreme Ultraviolet Lithography}

Donald Sweeney

Physics and Advanced Technologies Directorate

Microelectronic circuits are built-up layer-by-layer with very intricate patterns. This process of recording images of the circuit patterns onto the silicon wafer is called lithography. Maintaining robust growth of the semiconductor industry requires making circuit features smaller by developing more sophisticated lithographic processes. Extreme ultraviolet lithography (EUVL) is a lithography method that uses very short wavelength light-about $10 \mathrm{~nm}$ - to create veryhigh-resolution lithographic images. In fact, EUV light is capable of making images with 25-nm features, in comparison with current patterns, which have features of about $180 \mathrm{~nm}$ (a human hair is about $100,000 \mathrm{~nm}$ in diameter). This new technology is being developed by a consortium of three Bay Area national laboratories: LLNL, Sandia-California, and Lawrence Berkeley. Work is funded by a consortium of six semiconductor manufacturers under a Cooperative Research and Development Agreement (CRADA).

\section{Glucose Sensor}

\section{Steven Lane}

Physics and Advanced Technologies Directorate

A team of scientists at LLNL and MiniMed, Inc. are developing a minimally invasive device to monitor glucose levels; it will be fully implantable in the body and be able to measure glucose levels continuously. This new device is a fluorescent chemical sensor that consists of carefully engineered molecules embedded within a biocompatible polymer. In the absence of glucose, these molecules are nonfluorescent. However, glucose alters the electron configuration of these molecules so that they become fluorescent and emit light of a specific color. The intensity or brightness of this emitted light indicates the body's glucose level; a more intense light emission corresponds to a higher glucose level.

\section{Handheld Advanced Nucleic Acid Analyzer}

\section{Ronald P. Koopman}

Nonproliferation, Arms Control, and International Security Directorate

Shavnavaz Nasarabadi

Biology and Biotechnology Research Program

There is increasing awareness of the vulnerability of the U.S. civilian population to a biological terrorist attack. Indeed, the ability to accomplish such an attack does not require particularly sophisticated technology or large amounts of a biological agent. In response to this threat, LLNL has made major advances in biodetection, including the Handheld Advanced Nucleic Acid Analyzer (HANAA), which is the first truly portable DNA analysis instrument suitable for real-time identification of bioagents in the field. Originally developed for the defense and intelligence communities to detect biological agents that might be used on the battlefield or in a terrorist attack, HANAA also has broad civilian health applications. Beta testing includes a project in Africa to identify drug-resistant malaria strains and a project at the Gulf Coast Seafood Laboratory in Alabama to detect bacteria and viruses in seafood and to analyze environmental samples from ships importing seafood.

\section{Hydrogen at Extreme Conditions: Building Jupiter in the Laboratory}

Neil Holmes and Gilbert Collins Physics and Advanced Technologies Directorate

Hydrogen is the simplest and most abundant element in the universe, yet at high pressure it is one of the most difficult to understand. The performance of inertial confinement fusion (ICF) targets and the interior models of the giant planets like Jupiter depend strongly on models of the properties of dense hydrogen in the high-pressure, high-temperature fluid phase. We use gas guns and lasers to re-create the conditions inside Jupiter in our laboratories. At conditions up to several million atmospheres and many thousands of degrees, hydrogen molecules break up and ionize. Under certain conditions, hydrogen becomes a metal! The poster describes recent experiments to measure the equation of state and electrical conductivity of dense hydrogen at these conditions. These experiments reveal deficiencies in $a b$ initio theories of dense hydrogen, but may point the way to improved theoretical treatments.

\section{Isotope Hydrology for Water Resources Management}

G. Bryant Hudson and Jean E. Moran Chemistry and Materials Science Directorate

We have been applying isotope hydrology to issues in water resource management over the past eight years. Recently we have begun a large-scale program in conjunction with the U.S. Geologic Survey for the State of California (State Water Resources Control Board) to evaluate ambient groundwater quality 
throughout all of California. This poster covers three areas: evaluation of California groundwater vulnerability, noble-gas artificial groundwater tracers, and tracking sources of uranium using isotope ratios.

\section{LLNL-Home to the World's Fastest Supercomputer \\ Mark Seager \\ Computations}

ASCI White is the fourth platform in the DOE Accelerated Strategic Computing Initative's (ASCI's) drive to a 100-teraop performance level. ASCI White is a partnership between LLNL and the IBM corporation. In June 2000 , this platform demonstrated a world-record 3.9 teraops delivered on a hydrodynamics benchmark, an achievement that eclipses the previous world record, set by ASCI Blue-Pacific in 1997, by over 325 percent.

\section{Matrix-Free Identification of Bacillus Spore Species Using Infrared Laser Desorption and Time-of-Flight Mass Spectrometry}

Joel Ullom and Simon Labov

Physics and Advanced Technologies

Kevin C. Langry

Nonproliferation, Arms Control, and International

Security Directorate

Rapid and accurate identification of microorganisms is desirable for a wide range of environmental and medical applications. While matrix-assisted laser desorption and ioniation time-of-flight (MALDITOF) mass spectrometry (MS) is already viewed as a promising tool to achieve this goal, some preparation of analyte materials is required; namely, the addition of a chemical matrix to enhance desorption and ionization. As a step towards real-time identification of microorganisms, we have performed mass spectrometry on intact bacterial spores with no matrix. Using infrared laser desorption and TOF-MS with no matrix, we have successfully differentiated between intact spores of several Bacillus species.

\section{Microfabricated Multifrequency Particle" Impedance Characterization System}

Peter Krulevitch, Chris Fuller, Julie Hamilton, and Harold Ackler

Engineering Directorate

Collaborators:

Adam Eldredge and Frederick Becker

Berkeley Sensor and Acutator Center at the

University of California, Berkeley
Iun Yang and Peter Gascoyne

University of Texas, M. D. Anderson Cancer Center

The microfabricated flow-through impedance characterization system is capable of performing $\mathrm{AC}$ broadband, multifrequency measurements on cells and other particles. The sensor characterizes multiple particle parameters at rates up to 100 particles per second by measuring both the resistive and reactive impedance of passing particles at three or more frequencies simultaneously. Applications include hematology, pharmacology, forensics, and counterbiological warfare.

\section{Modeling Complex Protein Structures}

Michael Thelen and Ceslovas Venclovas Biology and Biotechnology Research Program

Central to the survival of all organisms is the ability to sense and correct changes in DNA structure. Cellular response to the damaging effects of radiation, oxidation, or chemical modification of DNA involves many different proteins and multiprotein complexes. These protein units form the machinery to remove DNA damage and ensure faithful replication of the genome, events essential for the avoidance of cancer formation. The use of comparative genomics coupled with computational protein structure prediction methods has enabled us to describe several new DNA repair proteins related to protection from genetic instability and human disease. From these studies we have postulated a novel mechanism for eight proteins in the Rad checkpoint and Replication Factor C (RFC) protein complexes. Our objective is to predict in molecular detail the network of the checkpoint and replication protein complexes, and their interaction with damaged DNA structures. These predictions will be used to guide laboratory experimental studies to test the actual protein interactions and mechanisms.

\section{New Novel Materials at High Pressures and Temperatures}

Choong-Shik Yoo

Physics and Advanced Technologies Directorate

The field of high-pressure science has been central to many developments in condensed-matter material physics, solid-state chemistry, and earth and planetary sciences for many decades. High-pressure properties of weapons materials are also critical in the assessment of stockpile performance. Lately, with new developments of a third-generation synchrotron, microprobing laser spectroscopy, and diamond-anvil cell technology, high-pressure 
research is experiencing an unprecedented surge of breakthroughs in science and technology. In this poster, we present some of our recent discoveries, including polymeric carbon dioxide and new phases of 3-D magnetic elements.

\section{NUFT Simulations of Subsurface Reactive Flow and Transport}

John J. Nitao

Energy and Environment Directorate

Quantitative characterization of the physics and chemistry of fluid phases moving through the Earth's subsurface is a very significant application of the science of reactive flow and transport. The LLNLdeveloped Nonisothermal Unsaturated-Saturated Flow and Transport (NUFT) computer code, together with high-quality field and laboratory data and recent advances in high-speed computers, now make it possible to obtain accurate and dependable simulations of a wide variety of reactive flow and transport processes. Importantly, it allows us to use simulations to obtain a better understanding of many of the major issues in the geological sciences today.

\section{PEREGRINE}

\section{Christine Hartmann-Siantar}

Physics and Advanced Technologies

PEREGRINE is a highly accurate computer system for calculating where and how much radiation is absorbed in the body during radiation treatment for cancer and other diseases. Using the patient's CT scan for detailed information about the tumor and surrounding tissue, PEREGRINE accurately models the radiation beam delivery system for each planned treatment. PEREGRINE applies the Monte Carlo technique to simulate the trillions of radiation particles that enter the body during a treatment and then calculates the actual dose by using the Laboratory's extensive databases on nuclear and atomic interactions to model how the radiation interacts with the tissue in the patient's body. Because of PEREGRINE's accuracy, radiation therapy could become more effective for targeting tumors and safer for healthy tissue. The FDA recently granted clearance to the NOMOS Corporation, LLNL's commercial partner, to make PEREGRINE available for clinics throughout the U.S.

\section{Post-Doctoral Research in NIF Programs}

A. Bullock, D. Hicks, N. Izumi, M. Shirk, and K. Wharton NIF Programs Directorate

Post-doctoral scientist in NIF Programs are actively involved in a wide range of research ranging from short-pulse laser-target interactions to $x$-ray and neutron diagnostic technique development and equation-of-state measurements relevant to planetary astrophysics. Results from several different projects are presented.

\section{Progress in Indirect-Drive Inertial Confinement Fusion Experiments}

\section{O.L. Landen}

NIF Programs Directorate

Recent progress in studying the physics of indirectdrive inertial confinement fusion expected at NIFscale has been made principally through experiments conducted at the Omega laser facility. Current research encompasses all aspects of $\mathrm{X}$-ray driven implosions. In the area of laser light conversion to $x-$ rays, we now have a fuller characterization, by Thomson scattering and three-wave mixing, of the laser-plasma instability mechanisms in plasmas emulating those of gas-filled NIF-scale hohlraums. Ablator studies include measurements of shock, ablation, implosion speeds and instability growth rates in NIF-relevant ablator materials. Hohlraum flux-symmetry diagnosis using various surrogate capsules has demonstrated the required accuracy for eventual symmetry tuning in preparation for NIF ignition We have also repeatedly demonstrated performance that is close to 1-D and 2-D code predictions in high-convergence (20 x) implosions by using a NIF-like hohlraum illumination geometry.

\section{Protecting Information Networks}

Robert R. Burleson

Nonproliferation, Arms Control, and International Security Directorate

The U.S. must be able to defend critical infrastructures from nation-state, terrorist, or hacker attacks and to exploit information technology as a military strategy. Over the past several years, we have developed a world-class competency in information operations and technology that is enabling researchers, policy-makers, and implementers to understand the national security implications of global interconnectivity and to begin to address the problems posed by the nation's (and the world's) growing reliance on massive information networks. Elements of this work include (1) the Computer Incident Advisory Center (CIAC), a federal resource for incident response, indications and warning, attack analysis, and vulnerability assessments; (2) systems protection operations, which complements the CIAC by providing systemspecific cybersecurity analysis; (3) computer security 
technology; (4) information operations technology; and (5) advanced research and analysis.

\section{Research and Advanced Tools for Evaluation of Global Climate Models}

Karl E. Taylor and Gerald L. Potter

Energy and Environment Directorate

Research within the Program for Climate Model Diagnosis and Intercomparison (PCMDI) centers on its mission to perform systematic and comprehensive evaluations of global climate models. These models are being used to predict future changes in global climate, with increasingly unavoidable implications for energy and economic policy. Therefore, it is critical to use objective measures to characterize both the skill and current limitations of these models. Examples of PCMDI research and software tool development are provided, highlighting PCMDI's leading role in model evaluation.

\section{Scalable Algorithms And Software Framework Enable Large-Scale Scientific Simulations}

Robert Falgout, François Gygi, William Henshaw, and

Peter Brown

Computations Directorate

LLNL is conducting world-class research in support of scientific computational simulations in many areas. This poster highlights four of these areas: (1) scalable solvers increasingly show impressive gains in computational speed and efficiency; (2) integration of Newton's equations of motion with corresponding algorithmic improvements reveal the properties of molecules; (3) new software tools provide rapid implementation of high-resolution simulations involving complex moving geometry; and (4) ARDRA is a scalable, parallel code system for neutron and radiation transport calculations, such as those performed to model physics in the National Ignition Facility (NIF).

\section{The Search for Dark-Matter Axions}

Karl van Bibber and Darin Kinion

Physics and Advanced Technologies Directorate

In collaboration with the Massachusetts Institute of Technology, the University of California, Berkeley and the University of Florida, we have built the world's quietest radio receiver to search for the elusive axion, a hypothetical ultra-light elementary particle that may constitute the dark matter of the Universe. Axions forming our Milky Way galaxy's dark matter halo can resonantly convert into a weak radio signal (a trillionth of a trillionth of a Watt) in a microwave cavity permeated by a strong magnetic field. A next-generation experiment is now being designed, building upon a breakthrough technology-near-quantum-limited amplifiers called superconducting quantum interference devices (SQUIDs).

\section{A Single Molecule Study of DNA-Protein Interactions}

Laurence Brewer, Shelley Corzett, and Ron Balhorn Biology and Biotechnology Research Program

Single molecule studies provide kinetic and mechanistic information that is often obscured in bulk measurements. In our experiments, an optical trap is used to manipulate individual DNA molecules in a novel microfluidic flow cell to study important biological processes that take place in cells. In particular, we are interested in understanding how DNA is packaged by protamine in the mammalian sperm cell, a process that is important to male fertility, embryo development, and therapeutic treatments such as gene therapy. Having recently observed the coiling and uncoiling of the same DNA molecule by protamine, we were able to demonstrate that this packaging protein must be actively removed from sperm chromatin following fertilization; results were published in Science. We are also collaborating with a group at the University of California, Davis to study how DNA is unwound by the helicase enzyme RecBCD during genetic recombination, a process that is responsible for the generation of genetic diversity and DNA repair. We observed a single helicase enzyme unwind a single DNA molecule for the first time; results were recently reported in Nature.

\section{The Spheromak Path to Fusion}

David N. Hill and the SSPX Team

Physics and Advanced Technologies Directorate

Scientists at LLNL are exploring the spheromak as a potential fusion energy reactor. In the spheromak, the fusion fuel is insulated from material surfaces using magnetic fields generated by currents within the plasma itself. This may lead to cheaper, simpler fusion reactors than present designs. Experiments using the SSPX spheromak at LLNL are focused on understanding how the internal plasma currents produce the measured magnetic fields, and how well these fields insulate the plasma from the wall. 
STARS-Science and Technology Awards and Recognition System

http://stars.llnl.gov/

Pamela Harris

Laboratory Science and Technology Office

Created and maintained by the Laboratory Science and Technology Office (LSTO), STARS is LLNL's dynamic browser-based database system for tracking the honors and awards received by the LLNL scientific and technical community. The goals of STARS include increasing the visibility of LLNL's accomplishments in science and technology; publicly recognizing the achievements of LLNL's scientists and engineers; and promoting the nomination processes for prestigious awards. STARS users can search for scientific and technical awards received by LLNL employees, add an award to the STARS database, read descriptions of the awards included in STARS, and obtain information about citations of LLNL-authored publications in scientific and technical journals.

\section{Surface-Attached Interlocking Molecules \\ Glen Fox and Andrew Vance \\ Chemistry and Materials Science Directorate}

We are working to develop new mechanically interlocking molecules for the formation of multifunctional and tunable self-assembled monolayers. The long-term goal of the project is the creation of sensors with properties that can be controlled at the molecular level. Initial studies are directed toward the synthesis and characterization of model systems that we are calling surface-attached loops. Next, we will advance to the preparation of surface-attached interlocking molecules, known as catenanes and rotaxanes. This project is a collaborative effort between LLNL and Prof. Fraser Stoddart at UCLA.

\section{Surveying the Outer Solar System with Robotic Telescopes}

Stuart Marshall, Kem Cook, and Rodin Poratta Physics and Advanced Technologies Directorate

The region of the outer solar system beyond the orbit of Neptune, known as the Kuiper Belt, is populated with disk-like objects of planetary material, called Kuiper Belt Objects (KBOs), that provide clues about how the planets were formed. However, the populations and distributions of KBOs are not well known; uncertainties span orders of magnitude. We are carrying out novel surveys for both very large and very small objects in the Kuiper Belt using robotic telescopes. For objects larger than $200-\mathrm{km}$ across, we are using the highly automated Macho Telescope System in Canberra, Australia. At the other end of the size spectrum, we are pioneering an occultation technique with the Taiwanese American Occultation Survey (TAOS) project, which will enable us to detect objects as small as $2-\mathrm{km}$ across that are as much as 10,000 times fainter than those detected with existing searches.

\section{Synthesis of Nanocrystals with Tunable Sizes and Properties}

\section{Long N. Dinh and Mehdi Balooch}

Chemistry and Materials Science Directorate

We have synthesized a variety of nanocrystals with tunable sizes and properties. For single-element materials with fairly low melting temperatures (such as $\mathrm{Si}, \mathrm{Ge}$, or $\mathrm{Al}$ ), the technique of supersaturated physical vapor deposition produces nanocrystals with sizes tunable in the range of a few nanometers to many micrometers. Our experiments showed that the band gaps of semiconductor nanocrystals can be engineered by controlling the particle size. For dielectric materials with high melting temperatures such as $\mathrm{SiO}_{2}$ or $\mathrm{Y}_{2} \mathrm{O}_{3}$, the technique of pulsed-laser deposition (PLD) in a background gas has been employed to generate nanocrystals with physical and electronic properties that are different than bulk parent samples. Most recently, using femtosecond lasers, we have obtained stoichiometric compound nanocrystals with constituent elements differing greatly in vapor pressures, such GaAs and InP. These compound nanocrystals could not be produced previously with nanosecond lasers. This suggests that femtosecond PLD in a background gas is capable of producing a broad class of multi-element nanocrystals with the right stoichiometries.

\section{Technology for Fissile Material Storage and Warhead Dismantlement Transparency}

James F. Morgan

Nonproliferation Arms Control, and International

Security Directorate

John Luke

Chemistry and Materials Science Directorate

Since the early 1990s, the U.S. and Russia have been engaged in a wide range of negotiations to reduce the danger from nuclear weapons. Issues have included shutting down plutonium-producing reactors, monitoring nuclear stockpiles, mutual inspections of material declared excess to the weapons programs, and the final disposition of excess plutonium. Many of these negotiations have 
floundered on the shoals of classified information that would need to be exchanged in order to verify these agreements. As a way out of this impasse, Livermore and Los Alamos developed the concept of an information barrier-a set of hardware, software, and procedures that allows measurements on classified objects without revealing classified information to the inspectors. In 2000 , the U.S. successfully demonstrated such a system to a delegation of scientists and security specialists from the Russian Federation, thus making valuable headway on this difficult but essential monitoring aspect.

\section{Terascale Browser: Interactive Exploration of Large Data}

Sam Uselton

Computations Directorate

The CASC visualization effort is exploring visualization strategies aimed at very-large-3-D and time-varying scientific simulation data sets. The processing and bandwidth requirements for interactive exploration of very large data sets are daunting but possible, by using clever algorithms and judicious preprocessing. The Terascale Browser allows a user to interactively explore a large data set with a limited set of capabilities and then to select a subset of the data and pass it to a visualization tool.
The Virtual Valley: An Integrative Tool for Environmental Research, Education, Assessment, and Planning

William P. Dannevik and Douglas A. Rotman

Energy and Environment Directorate

The University of California recently launched a tenth campus, the University of California at Merced (UCM). Part of the UCM start-up strategy is a vigorous institutional-level research partnership with LLNL, including elements in environmental science, information technology, and engineering. The environmental science portion will focus on the challenges surrounding the rapid development and transformation of the California Central Valley and Sierra Nevada region. The Virtual Valley represents a joint LLNL/UCM vision for a comprehensive environmental simulation and observation system that will embrace and integrate current trends in key technology areas: advanced sensors, wireless communication simulation, geographical information systems, and advanced visualization. 